\title{
Cooling and crystallization at an inclined plane
}

\author{
Herbert E. Huppert ${ }^{1}$, R. Stephen J. Sparks ${ }^{2}$, J. Richard Wilson ${ }^{3}$ and Mark A. Hallworth ${ }^{1}$ \\ ' Department of Applied Mathematics and Theoretical Physics, University of Cambridge, Silver Street, Cambridge CB3 9EW (England) \\ 2Department of Earth Sciences, University of Cambridge, Downing Street, Cambridge CB2 $3 E Q$ (England) \\ ${ }^{3}$ Department of Geology, Aarhus University, Aarhus (Denmark)
}

Received March 3, 1986; revised version accepted June 9, 1986

\begin{abstract}
Experiments have been carried out on the cooling and crystallization along an inclined plane of aqueous solutions of $\mathrm{Na}_{2} \mathrm{CO}_{3}$ in order to investigate convective effects and the development of compositional zonation. The formation of crystals of $\mathrm{Na}_{2} \mathrm{CO}_{3} \cdot 10 \mathrm{H}_{2} \mathrm{O}$ causes adjacent fluid to become relatively light because it is depleted in $\mathrm{Na}_{2} \mathrm{CO}_{3}$. When crystallization occurs at an inclined roof the behaviour is similar to previous results for crystallization and the release of light fluid at a vertical boundary. A compositional boundary layer of light residual fluid flows along the sloping roof and forms an upper region of strong chemical stratification. This gradient region increases in depth with time and is separated by a sharp interface from a region of homogeneous solution below. Eventually the whole depth of fluid becomes chemically stratified. When crystallization occurs along an inclined floor thin plumes of light residual fluid rise vertically from the slope with strong compositional boundary layer flows up the slope. The combination of this boundary flow and the horizontal variation in the length of the plumes leads to development of compositional stratification throughout the solution. A steep gradient develops at the top which grades down into a weaker gradient in the central and lower region. The shape and magnitude of the chemical gradients depend on the geometry of the tank adjacent to the slope. Stronger compositional gradients are developed in tanks with larger ratios of width to depth. The experiments suggest that compositional zoning can develop in magma chambers by crystallization along an inclined floor even if the angle is quite small. Differentiated residual magma should move laterally up the slope and margins to accumulate at the roof. We suggest that this process was the main cause of strong compositional zoning in thesill-shaped Hyllingen Series, part of the Caledonian Fongen-Hyllingen layered intrusion, Norway, where crystallization occurred entirely along an inclined floor.
\end{abstract}

\section{Introduction}

Experiments on the cooling and crystallization of aqueous solutions in laboratory tanks have provided many new insights into the processes that can occur within magma chambers and on the origin of compositional zoning. Cooling an aqueous solution below its liquidus at a boundary wall causes crystals to form at the boundary, which releases fluid depleted in the solute. The motion of this released fluid, combined with thermally driven fluid motion, has been studied for the cases of cooling along horizontal and vertical boundaries [1-5]. In the case of a vertical margin, compositional boundary layer flows cause strong chemical gradients to develop and this process has been proposed as the origin of zoning in magma chambers [2-4]. Thermally driven fluid motion produced by cooling along an inclined surface has been studied by Irvine [6] and models involving the crystallization of the Stillwater and Muskox intrusions along inclined floors have been proposed $[7,8]$.

In the series of experiments described here we examine the effects of cooling and crystallization along inclined boundaries. The geological motivation for this is that the walls of magma chambers are seldom vertical or horizontal surfaces. In the specific case of the Fongen-Hyllingen intrusion, Norway, crystallization occurred along a sloping floor [9], and geological and petrological evidence indicates that the magma chamber developed strong compositional zonation. In many reconstructions of magma chambers, inwardly inclined margins or floors are depicted and the real margins may be even more complex. The experiments described in this paper indicate that compositional zoning can be developed in a wide variety of chamber geometries. 


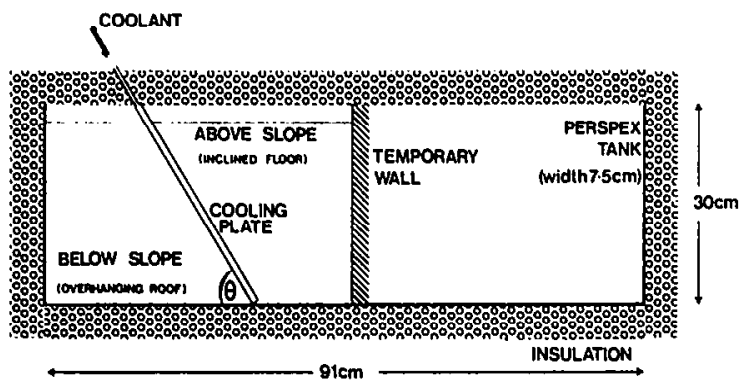

Fig. 1. Geometry of the tank used for cooling and crystallization of aqueous solutions along an inclined boundary. Experiments were performed at slopes of $90^{\circ}, 70^{\circ}, 45^{\circ}$ and $20^{\circ}$.

\section{Apparatus}

The experiments were conducted in a Perspex container $30 \mathrm{~cm}$ high and $7.5 \mathrm{~cm}$ wide whose length could be varied up to $91 \mathrm{~cm}$ (Fig. 1). The walls, roof and floor of the tank were insulated with polystyrene which could be removed for observation by means of the shadowgraph technique. Coolant was circulated through a thin, rectangular box made of copper. The coolant was fed through a long rod within the box and released at its base.
It then circulated up the box and was withdrawn at the top. The box was covered with wire gauze to inhibit nucleating crystals falling off the cooling surface. The cooling box was movable to allow the angle of slope to be varied. In many of the experiments, the same volume of fluid (nominally 4.9 litres) was used on either side of the slope, which allowed intercomparisons between experiments with different slope angles. An important feature of the apparatus was that it permitted simultaneous study of cooling below the slope (an overhanging wall) and above the slope (an inclined floor).

A 12.8 wt.\% sodium carbonate $\left(\mathrm{Na}_{2} \mathrm{CO}_{3}\right)$ solution was used in all but one experiment. This has a liquidus just below room temperature, at about $13^{\circ} \mathrm{C}$, and the eutectic with ice is $-2^{\circ} \mathrm{C}$ at 6.1 wt.\% $\mathrm{Na}_{2} \mathrm{CO}_{3}$ (Fig. 2a). Angles of $90^{\circ}$ (vertical), $70^{\circ}, 45^{\circ}$ and $20^{\circ}$ were all utilized. In all experiments the temperature of the coolant was decreased from room temperature to $-21.5^{\circ} \mathrm{C}$ in about 1 hour and was then maintained at $-21.5^{\circ} \mathrm{C}$ for the remainder of the experiment. Crystallization of $\mathrm{Na}_{2} \mathrm{CO}_{3}$ releases buoyant fluid; thus for comparative purposes, a final experiment on a $45^{\circ}$

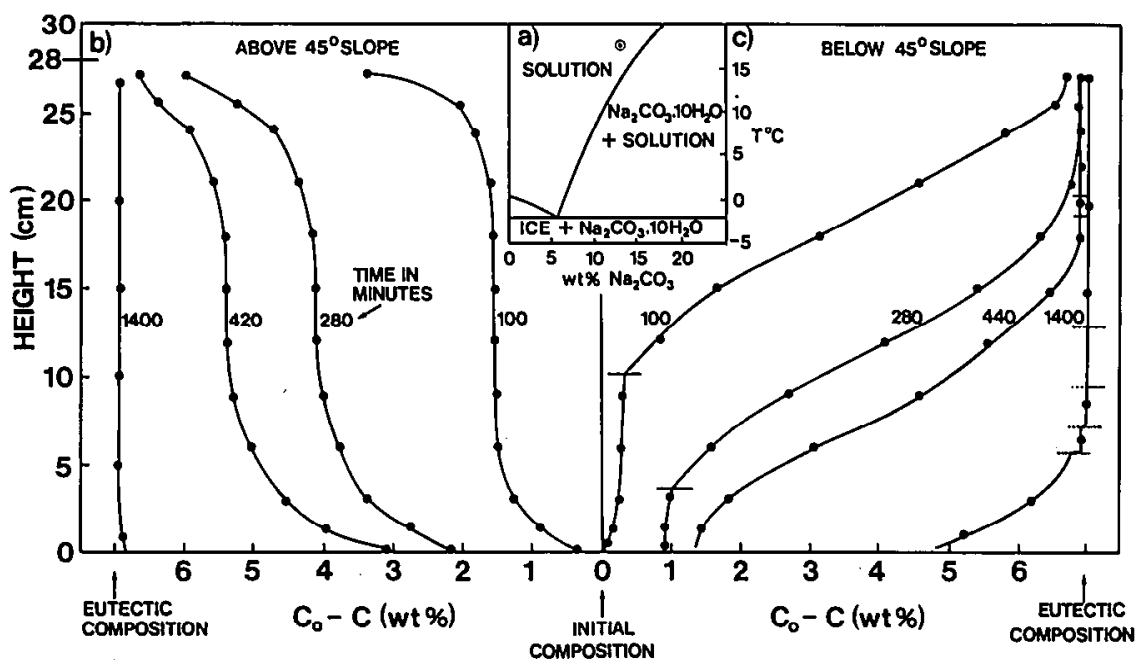

Fig. 2. (a) Binary eutectic system for $\mathrm{H}_{2} \mathrm{O}$ and $\mathrm{Na}_{2} \mathrm{CO}_{3}$ showing the composition of the initial solution in the experiments: 12.8 wt. $\%$ $\mathrm{Na}_{2} \mathrm{CO}_{3}$ and initial temperature about $17^{\circ} \mathrm{C}$. The liquidus curve at this composition is at $14^{\circ} \mathrm{C}$. The eutectic point is $-2^{\circ} \mathrm{C}$ at 6 wt. $.5 \mathrm{Na}_{2} \mathrm{CO}_{3}$. (b, c) Composition profiles with time above (b) and below (c) a $45^{\circ}$ slope. The times when the profiles were measured are indicaled in minutes. Fluid was initially $28 \mathrm{~cm}$ deep. Horizontal lines on the profiles of 100 and 280 minutes on (c) indicate the position of the sharp interface between the chemically stratified region and the lower convecting homogeneous region (the "filling box" interface). The dashed horizontal lines on the 400 and 1400 minute profiles indicate the positions of double-diffusive interfaces. 
slope was performed with an aqueous $\mathrm{NaNO}_{3}$ solution for which the crystallization of ice results in the release of relatively dense fluid.

\section{Results}

Cooling and crystallization of a 12.8 wt.\% $\mathrm{Na}_{2} \mathrm{CO}_{3}$ solution along a $45^{\circ}$ slope will initially be described, followed by a discussion of the influence of different slopes. Cooling and crystallization of a 14 wt.\% $\mathrm{NaNO}_{3}$ solution will then be described briefly. Our description concentrates on the cases in which the slope was placed mid-way in the working section of the Perspex container, as shown in Fig. 1.

\subsection{Above $45^{\circ}$ slope (inclined floor)}

A thermal boundary layer became visible after about 4 minutes. Fluid in the layer moved down the slope and out along the base of the tank. After about 13 minutes, crystals of $\mathrm{Na}_{2} \mathrm{CO}_{3} \cdot 10 \mathrm{H}_{2} \mathrm{O}$ began to form at the base of the cooling plate, producing small plumes of buoyant released fluid. Crystallization began at the base because cooled and supersaturated fluid had accumulated at the bottom of the tank due to thermal convection. In addition, there was a slight $\left(<1^{\circ} \mathrm{C}\right)$ decrease of temperature down the plate, because coolant emerged at its base. Crystals gradually nucleated further up the slope and covered most of the plate after about $1 / 2$ hour. The downslope, thermally driven motions gradually weakened and buoyant compositional convective motion became completely dominant after some 45 minutes. The buoyant released fluid from the crystallizing $\mathrm{Na}_{2} \mathrm{CO}_{3} \cdot 10 \mathrm{H}_{2} \mathrm{O}$ ascended in numerous thin plumes. The plumes were typically unsteady, with vortex shaped structures developing at their head, and gradually mixed with the resident fluid in the tank during ascent. The width of individual plumes was estimated to be much less than $1 \mathrm{~mm}$. After about 50 minutes ice crystals joined $\mathrm{Na}_{2}-$ $\mathrm{CO}_{3} \cdot 10 \mathrm{H}_{2} \mathrm{O}$ at the base of the plate. This eutectic crystallization occurred when the coolant temperature had decreased to about $-14^{\circ} \mathrm{C}$. Some 30 minutes later the plate was covered by a mat of crystals, consisting of an inner white compact layer of ice plus $\mathrm{Na}_{2} \mathrm{CO}_{3} \cdot 10 \mathrm{H}_{2} \mathrm{O}$ and an outer layer of spikey, white/pale grey $\mathrm{Na}_{2} \mathrm{CO}_{3} \cdot 10 \mathrm{H}_{2} \mathrm{O}$.

At this stage in the experiment the overall circulation in the tank was observed by allowing crystals of potassium permanganate to fall through the fluid to leave an initially vertical steak of dyed fluid (Fig. 3a). In some experiments dye was also injected close to the front of crystallization at the base of the slope. The vertical dye streak showed that in the upper part of the fluid, motion was away from the slope, whereas in the lower part motion was towards the slope (Fig. 3a and b). Although the thin plumes rising from the crystals gave an impression that motion was predominantly vertical, injection of dye at the base of the slope showed that this impression was misleading. The dye revealed substantial motion along and up the slope with a strong boundary layer flow within, and several millimetres above, the crystal mush. Thus the motion of the compositionally depleted fluid was strongly up the slope rather than vertical. This behaviour can be attributed to the gross circulation of fluid within the tank and the requirement that there must be an inward horizontal flow of fluid towards the slope to balance the release of light fluid by crystallization. This is broadly in agreement with the convective pattern suggested by Irvine [7].

Measurements of the refractive index of the fluid extracted along a vertical line showed the evolution of the compositional gradients that developed in the fluid (Fig. 2b). A strongly stratified upper region developed in the first few hours. The surface solution reached a composition close to the eutectic (6.1\% wt. $\mathrm{Na}_{2} \mathrm{CO}_{3}$ ) after about 280 minutes, while at the base the fluid remained close to its starting composition $\left(10.7 \% \mathrm{Na}_{2} \mathrm{CO}_{3}\right)$. The steepest chemical gradients developed at the top and bottom of the solution, while a rather uniform central region only developed a weak gradient. A distinct interface between the upper, strongly stratified region and the central, uniform region was not observed, the transition being entirely gradual. After 23 hours, when the experiment was terminated, the upper $24 \mathrm{~cm}$ of the fluid had reached the eutectic composition while the lower 3 $\mathrm{cm}$ was compositionally graded. This basal stratification may be due to the fact that the upper surface of the cooling box did not extend to the base of the tank and a stagnant layer developed which was not as strongly cooled from the side as the fluid above it. By the end of the experiment, the eutectic crystallization front had caught up 

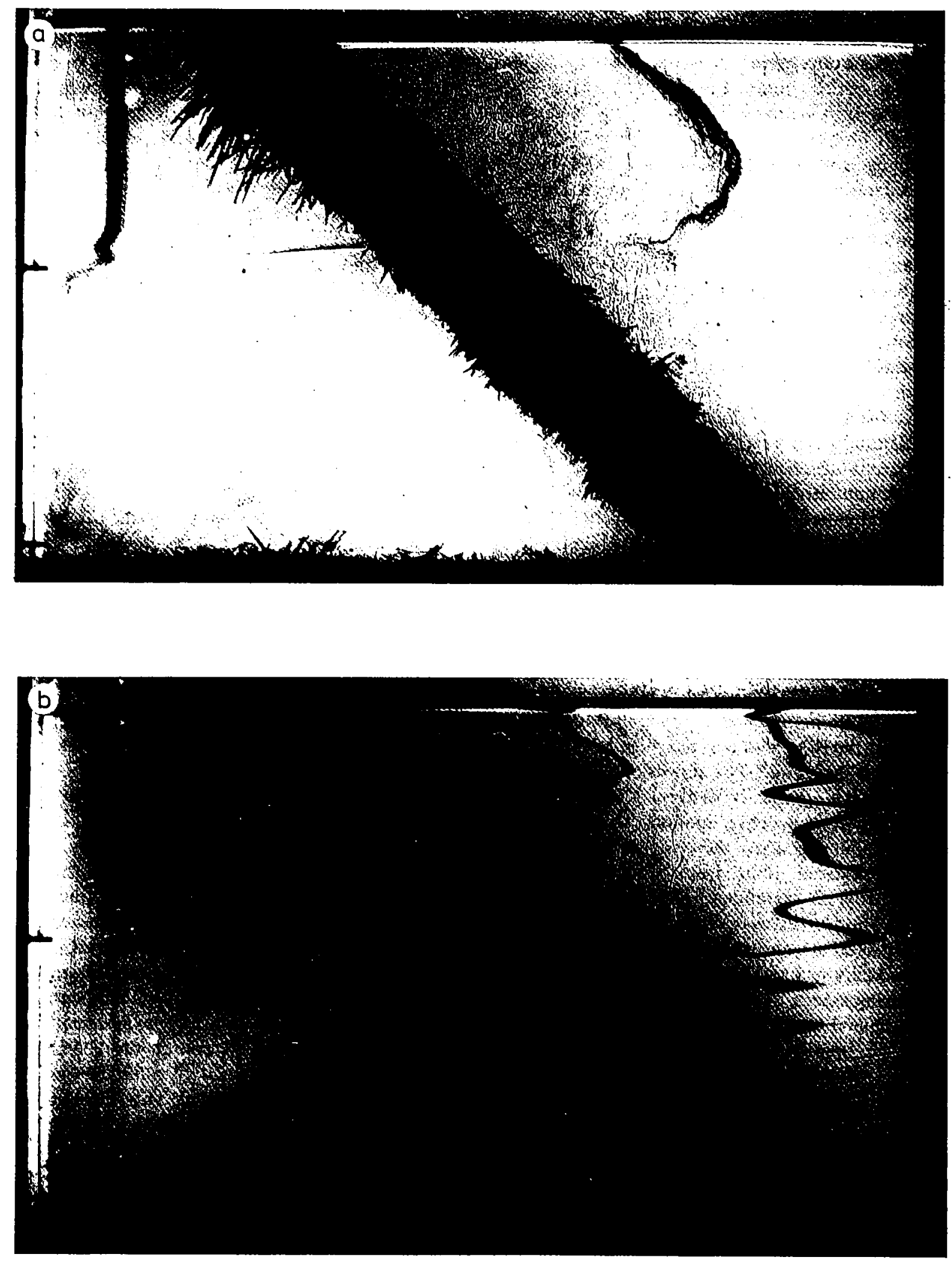


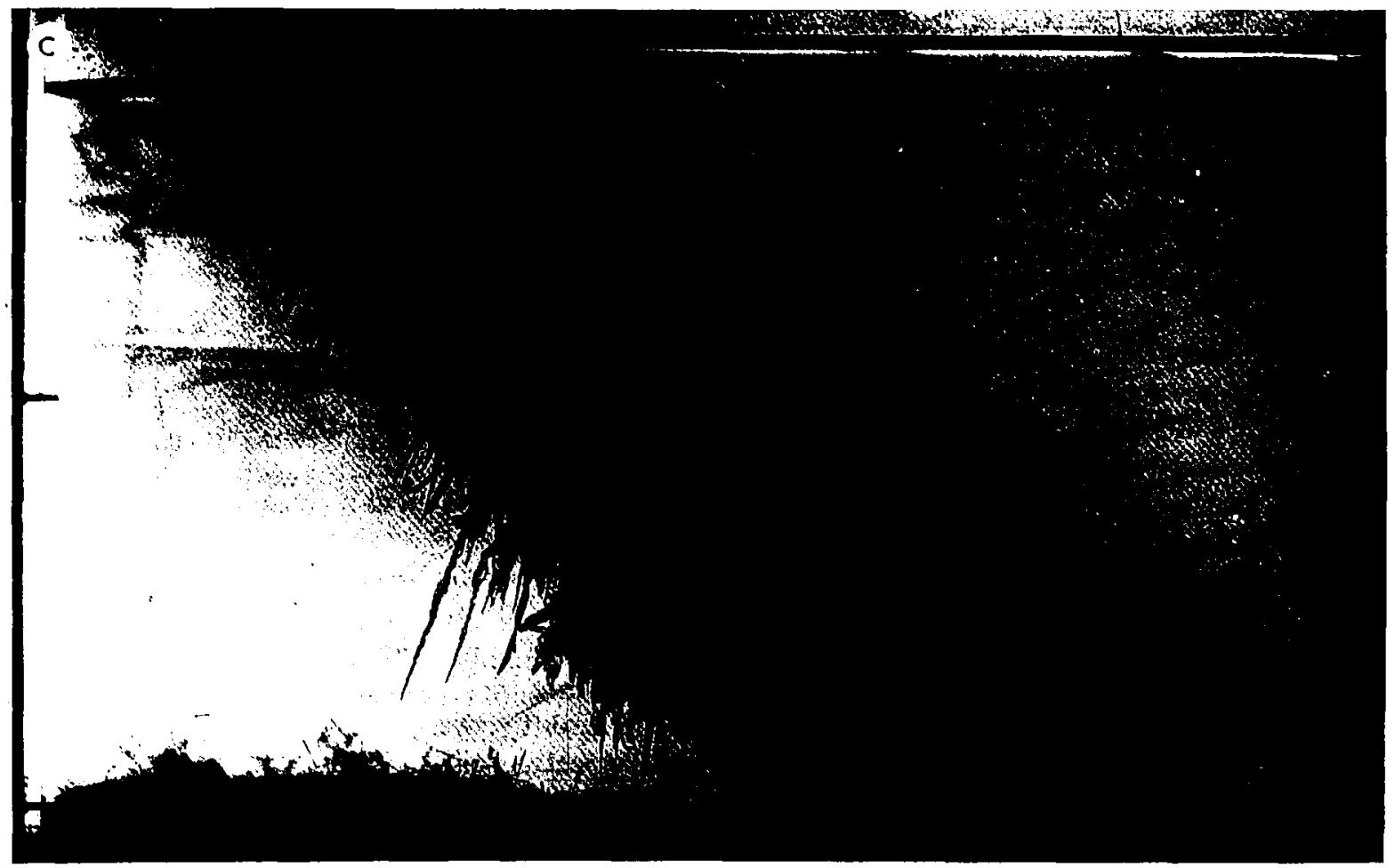

Fig. 3. Three photographs of an experiment with an aqueous solution of $\mathrm{Na}_{2} \mathrm{CO}_{3}$ and a $45^{\circ}$ slope taken at (a) 80 minutes, (b) $\mathrm{S}$ hours, and (c) 8 hours, after the commencement of the experiment.

with the $\mathrm{Na}_{2} \mathrm{CO}_{3} \cdot 10 \mathrm{H}_{2} \mathrm{O}$ crystals to form a sharp front between solid and liquid. A mushy zone (a mixture of crystals and liquid) only occurred in the lowermost $2-3 \mathrm{~cm}$, where compositional stratification remained. Very weak compositional convection was still visibly rising from the $\mathrm{Na}_{2} \mathrm{CO}_{3} \cdot 10 \mathrm{H}_{2} \mathrm{O}$ crystals in this lower non-eutectic region. The compositional gradients in the fluid were quite strong at times (Fig. 2b), and only rather weak double-diffusive layers developed in the lower non-eutectic region towards the end of the experiment (Fig. 3c).

\subsection{Below $45^{\circ}$ slope (overhanging wall)}

Initially only thermal convection occurred and an irregular thermal boundary layer developed beneath the plate. Although parcels of dense fluid were observed to separate from the boundary layer, and mix into the underlying solution, there was a considerable component of downward motion parallel to the plate and a net circulation of fluid within the tank. Crystallization of $\mathrm{Na}_{2} \mathrm{CO}_{3} \cdot 10 \mathrm{H}_{2} \mathrm{O}$ commenced at the base of the cooling plate after about 20 minutes, with the released, buoyant fluid forming a very thin boundary layer which flowed up the plate between the growing crystals. Some small crystals dislodged themselves and sank to the floor of the container. Downward thermal motion was observed in the near-plate region for about the first hour.

A compositionally stratified buoyant layer started to accumulate at the top of the fluid after about 25 minutes as a result of depleted fluid flowing up the roof. This buoyant layer was separated by a sharp horizontal interface from the well-mixed layer of denser, relatively undepleted fluid below. The interface gradually moved downwards (the "filling box" process [10]) so that after 100 minutes it was about $10 \mathrm{~cm}$ above the base of the tank (Fig. 3a). The composition of the fluid near the surface was almost at the eutectic and the $\mathrm{Na}_{2} \mathrm{CO}_{3}$ content gradually increased with depth down to the interface, below which it remained very close to the initial amount (Fig. 2c). Dye 
streaks showed that there was only very weak convective motion above the interface, with slow flow away from the plate near the surface, while below the interface the fluid continued to convect quite vigorously, strongly aided by compositional convection from the further growth of crystals which had broken away from the cooling surface and sank to the floor of the container (Fig. 3a). $\mathrm{Na}_{2} \mathrm{CO}_{3} \cdot 10 \mathrm{H}_{2} \mathrm{O}$ crystals growing into the upper, depleted layer developed as long, spikey dendrites with some secondary dendritic growth also. In comparison a denser mat of $\mathrm{Na}_{2} \mathrm{CO}_{3} \cdot 10 \mathrm{H}_{2} \mathrm{O}$ crystals developed from and into the lower layer (Fig. 3a). The $\mathrm{Na}_{2} \mathrm{CO}_{3} \cdot 10 \mathrm{H}_{2} \mathrm{O}$ crystals above the interface showed a marked tendency to project down towards the base of the tank at an angle between $50^{\circ}$ and $80^{\circ}$ to the cooling plate. Crystallization of ice at the eutectic started after about 70 minutes and this eutectic growth front gradually enveloped the $\mathrm{Na}_{2} \mathrm{CO}_{3} \cdot 10 \mathrm{H}_{2} \mathrm{O}$ crystals. After 7 hours the eutectic front varied in thickness from $5 \mathrm{~cm}$ at the top to $3 \mathrm{~cm}$ at the base of the cooling plate. The $\mathrm{Na}_{2} \mathrm{CO}_{3} \cdot 10 \mathrm{H}_{2} \mathrm{O}$ spines had been overtaken in the top $8 \mathrm{~cm}$, and the entire fluid was compositionally graded. By 23 hours most of the tank was filled with homogeneous fluid of eutectic composition, except for the lowermost $7 \mathrm{~cm}$ (Fig. 2c).

\subsection{Comparison of the above- and below-slope sides}

The bulk composition of the fluid remaining in the tank was evaluated as a function of time using compositional profiles like those shown in Fig. 2. Fig. 4 shows these data for the $45^{\circ}$ slope experi-

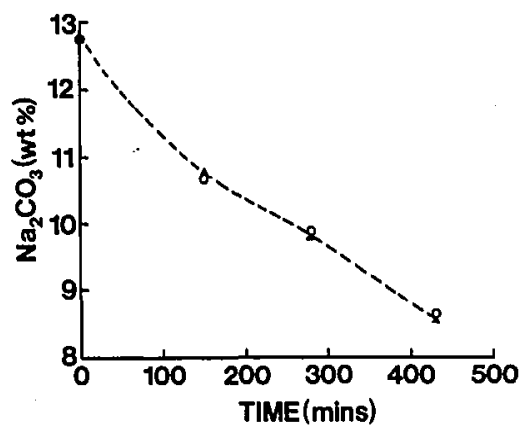

Fig. 4. The bulk composition of the solution remaining in the tank is shown as a function of time for the above slope (O) and below slope ( $\Lambda$ ) sides. The bulk evolution of the solutions are very similar. ment and demonstrates that the variation of the bulk compositions are essentially identical on the two sides of the plate. The only difference is in the compositional gradients developed in the two sides, as indicated in Fig. 2.

There are significant differences in the stratification of the upper region in the early stages of evolution. Fig. 5 compares stratification in the upper region at various times for the two sides at a slope of $45^{\circ}$. The gradients on the side below the slope are always stronger and the fluid at the very top is much more evolved.

\subsection{Influence of slope-angle on the above-slope} side

Experiments were carried out at slope angles of $20^{\circ}, 45^{\circ}, 70^{\circ}$ and $90^{\circ}$ with a constant volume of solution. The resultant profiles are shown for various times in Fig. 6. Surprisingly, there are only minor differences in the chemical evolution and chemical stratifications at various times. In the $90^{\circ}$ case, in the early stages the depleted solution rises entirely to the top of the tank with no mixing with the interior solution which maintains its original composition. With the other slopes there is slow evolution of the interior solution from the beginning of the experiment owing to the vertical
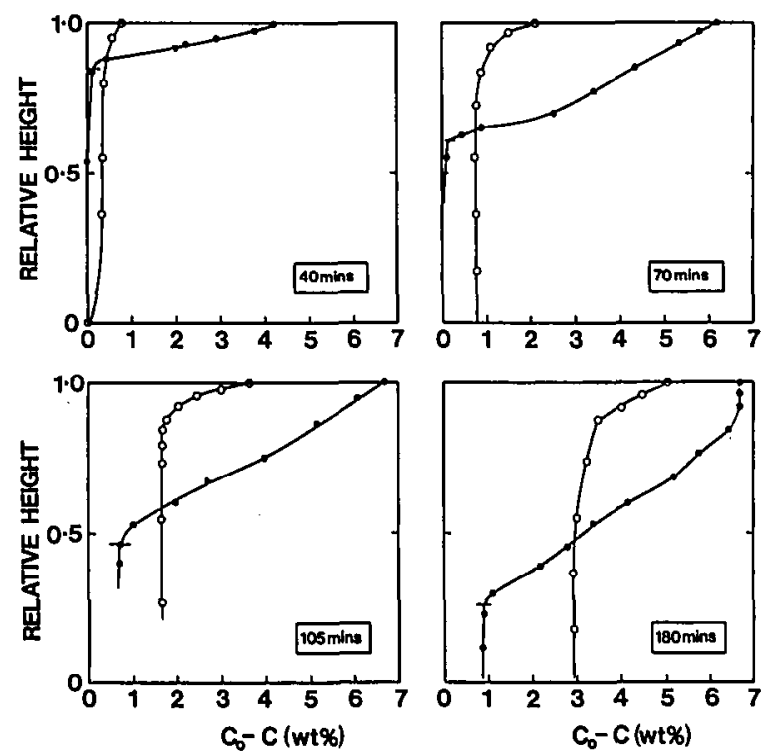

Fig. 5. Comparison of compositional stratification in above (O) and below (0) slope sides in the early stages of experiments for $45^{\circ}$ slopes. Times are indicated on each graph. 


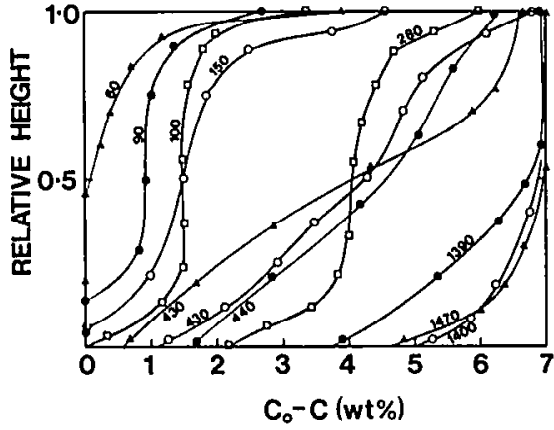

Fig. 6. Compositional profiles of solutions for slopes of $20^{\circ}$ $(\bullet), 45^{\circ}(\square), 70^{\circ}(O)$ and $90^{\circ}(\triangle)$ in experiments involving crystallization above the slope. The time in minutes for each profile is indicated. The profiles for the 4 slope angles are for early, intermediate and late times during the experiment.

rise of some depleted solution, but the predominant effect is the development of a strongly stratified upper region. In the early stages (60-150 minutes) the solution grades down into a rather uniform central region which nevertheless is still weakly stratified. At times beyond 400 minutes the experiments with slopes of $90^{\circ}, 70^{\circ}$ and $20^{\circ}$ show stratification throughout the tank with no major difference even between the vertical $\left(90^{\circ}\right)$ and $20^{\circ}$ slope. However, the $45^{\circ}$ slope shows a much weaker gradient in the central region than in the other experiments.

Although the most conspicuous visual feature in the above slope experiments is the vertical rise of thin plumes away from the slope, the most important process appears to be the flow of a compositional boundary layer up and along the slope. Injecting dye at the base of the slope confirmed that this boundary layer flow occurred in all the experiments.

One problem with comparing experiments in which the volume of solution remains constant and the slope angle varies is that the geometry of the tank changes. The aspect ratio (width to height) increases and the surface area of the cooling plate increases with decreasing slope. The former effect was investigated by comparing an aspect ratio of 1.5 with an aspect ratio of 2.5 for an angle of $45^{\circ}$. (The width is calculated as the distance from the sloping boundary to the end wall at $15 \mathrm{~cm}$ above the base of the tank.) Fig. 7 shows the two sets of data. The larger aspect ratio takes much longer to evolve to a given chemical stratification, because

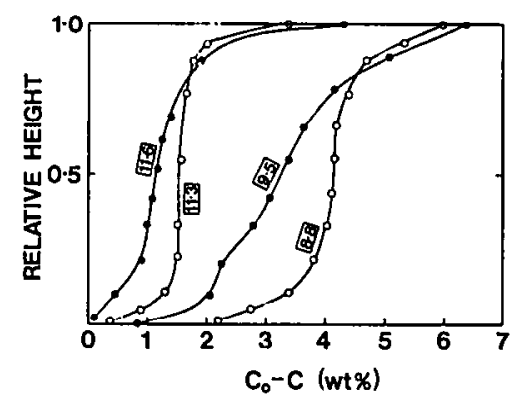

Fig. 7. Comparison of two experiments with a slope of $45^{\circ}$ on the above slope side. The two experiments differ in tank geometry and total fluid volume. One experiment $(0)$ has an aspect ratio of 1.5 and the other (e) has an aspect ratio of 2.5 . The figures by each curve are estimates of the bulk composition of the fluid in the tank as weight percent $\mathrm{Na}_{2} \mathrm{CO}_{3}$. At comparable stages of evolution the experiment with the larger aspect ratio develops stronger stratification.

of the much larger volume of fluid involved. The two experiments are most usefully compared when they have reached the same bulk composition. In the experiment with the larger aspect ratio the stratification is more pronounced with the fluid at the top being more evolved than in the other experiment at the same stage of overall evolution. The fluid in the central and lower regions is less evolved in the larger aspect ratio experiment, but the chemical stratification is stronger.

\subsection{Influence of slope angle on the below slope} side

The overall behaviour of the experiments with different slope angles was very similar (Fig. 8). A discrete stratified region developed above a homo-

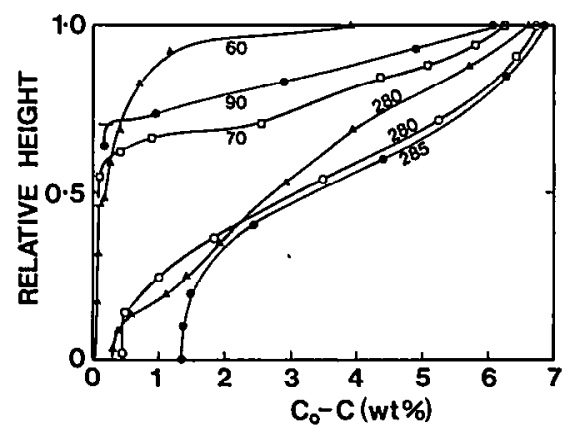

Fig. 8. Compositional profiles of solutions for slopes of $20^{\circ}$ $(\odot), 45^{\circ}(\mathrm{C}), 70^{\circ}(\mathrm{O})$ and $90^{\circ}(\Delta)$ in experiments involving crystallization below the slope. The time in minutes for each profile is indicated. 
geneous convecting region as described in detail for the $45^{\circ}$ experiment. Minor differences in the composition gradients at similar times are apparent. These may reflect differences in the tank geometry, room temperature, and surface area of the cooling plate, which changed with slope angle. However, the differences are not systematic or large and the major conclusion is that the rates of evolution and stratification are similar.

\subsection{Cooling and crystallization of a $14 \mathrm{wt} . \%$} $\mathrm{NaNO}_{3}$ solution along a $45^{\circ}$ slope

This experiment was performed to contrast the fluid motions observed when crystallization releases dense residual fluid. $\mathrm{A}$ dilute $\mathrm{Na}_{2} \mathrm{CO}_{3}$ solution could have been used, lying to the left of the eutectic in Fig. 2a, but the eutectic point lies at only 6.1 wt. $\% \mathrm{Na}_{2} \mathrm{CO}_{3}$ and the field of ice crystallization is rather small. Therefore a 14 wt.\% $\mathrm{NaNO}_{3}$ solution was employed, whose liquidus lies at $-5.3^{\circ} \mathrm{C}$ and the eutectic is $38.5 \mathrm{wt} . \%$ $\mathrm{NaNO}_{3}$ at $-17.5^{\circ} \mathrm{C}$.

Above the slope, dense residual fluid released by the crystallization of ice flowed down the slope to the floor of the tank. A sharp interface above the dense fluid gradually rose and reached a height of $15 \mathrm{~cm}$ after about 5 hours. Many double-diffusive layers developed in this lower stratified region. After 5 hours the fluid at the base of the tank had reached a composition of $26 \mathrm{wt} . \% \mathrm{NaNO}_{3}$ while above the interface it remained uniformly at its initial composition. After 24 hours the filling box interface had reached the surface and the entire fluid was compositionally graded with numerous double-diffusive layers. A few small ice crystals occasionally detached from the crystallization front and rose vertically to the surface throughout the experiment. No crystallization of $\mathrm{NaNO}_{3}$ was observed either above or below the slope.

Below the slope, dense compositional convective plumes descended essentially vertically towards the floor from ice crystals growing on the cooling plate, though some deflection of the plumes towards the plate was visible in the upper region where thermal convection influenced their motion. After 5 hours the fluid below about $8 \mathrm{~cm}$ was compositionally graded, reaching 21 wt. $\% \mathrm{NaNO}_{3}$ at the base, while above $8 \mathrm{~cm}$ the entire fluid had become enriched by about 1 wt. $\% \mathrm{NaNO}_{3}$ relative to the starting composition. Injection of dye revealed that there was a strong boundary layer flow down the slope rather than vertically; this is in principle similar to the motion observed in the above slope case when crystallization releases buoyant fluid, as described above. After 24 hours the fluid at the surface and floor had reached compositions of about $17 \mathrm{wt} . \%$ and $25 \mathrm{wt} . \%$ $\mathrm{NaNO}_{3}$ respectively. Double-diffusive layers were present throughout the fluid after about 6 hours.

The experiment confirmed that, at least qualitatively, the release of dense fluid either above or below a slope leads to the same motions as the release of relatively light fluid on the other side of the slope.

\section{Discussion}

Previous studies of cooling and crystallization of aqueous solutions have considered vertical and horizontal boundaries [1-5]. In the case of vertical boundaries, release of solute-depleted fluid generates compositional boundary layer flows which ascend (or descend) to produce strong compositional stratification by the filling box mechanism. For the case of light residual liquids, changing slope angle on an overhanging boundary was not anticipated to produce any major change in behaviour since the compositional boundary layer would flow up along the underside of the boundary to produce the same stratification and filling box phenomena. Our experiments have confirmed that this is indeed what happens.

In the case of an inclined floor, the experiments have produced effects which are rather different to those that were originally expected. In the case of crystallization from a horizontal floor, light residual liquid rises and mixes with overlying fluid which remains homogeneous but changes composition with time [1-5]. We had anticipated that light fluid rising from an inclined slope would have the same effect of keeping the fluid well-mixed and preventing chemical stratification from developing. The experiments, however, show that chemical stratification develops even with an angle as low as $20^{\circ}$.

We can identify two effects which cause chemical stratification to develop. One effect is geometrical and relates to the distance that the vertical plumes have to traverse from the slope to the top 
of the fluid. In the experiments the rate of production of buoyant fluid is approximately constant along the slope at any time. Plumes leaving the slope near the top will not mix much with dense fluid so reach the top close to their initial low density. However, at points further down slope the amount of mixing increases and the plumes becomes denser as they rise. In practice horizontal density gradients cannot be sustained, so a horizontal flow and a vertical stratification develops. This effect causes the weak density gradients observed throughout the central region (Figs. 2 and 6).

The second effect is the development of compositional boundary layers which predominantly sweep residual fluid up the slope Injecting dye at the base of the slope showed that this lateral upslope flow always dominated the thin plumes rising from the crystals. The reason for the strong lateral component of flow along the slope is that fluid from the interior is drawn towards the slope to replace the residual solution rising from the crystals. We suggest that this effect is responsible for the steeper gradients in the upper region and probably also contributes to producing the weaker gradients throughout the fluid.

The implications of the experiments for magma chamber processes are considerable. Previously it has been assumed that compositional zonation would be developed along the steeply inclined margins or along the roof of a magma chamber $[11,12]$. It was not thought that crystallization along inwardly inclined walls or along floors generating light residual fluid would be able to cause significant stratification. The experiments suggest otherwise. Fig. 9 shows how zonation could be produced along a chamber with a flat roof and inwardly inclined floor. A number of large layered intrusions have cross-sections with this geometry, including the northern part of the Fongen-Hyllingen intrusion [9], the Muskox intrusion [7], the Jimberlana intrusion [13] and the Great Dyke [14]. In the situation in which light, residual fluid is released, the overall sense of circulation in the magma chamber is opposite to that produced by thermal effects. A vertical sidewall does not appear to be required to cause compositional zonation. Even if crystallization occurs predominantly at the base of a magma chamber there is a strong tendency for differentiated fluid to collect at the top. In the situation in which dense residual fluid is released, the sense of circulation will be opposite and the differentiated fluid will collect at the base of the chamber [15].

In the case of the Hyllingen Series, part of the Fongen-Hyllingen intrusion, Norway [9], crystallization occurred entirely along the floor; there is no marginal border group and significant sidewall crystallization did not take place. Discordant relations between modal and cryptic layering developed in response to in situ crystallization of compositionally zoned magma along an inclined floor in a sill-shaped magma chamber with a flat roof. Despite the absence of side-wall crystallization, strong compositional stratification developed, ranging from gabbroic liquids at the base (producing olivine $\mathrm{Fo}_{75}$ and plagioclase $\mathrm{An}_{63}$ ) to quartzbearing syenitic magma at the roof ( $\mathrm{Mg}$-free mafics, plagioclase $A n_{01}$ ). The experiments suggest that this compositional stratification could have been readily accomplished by crystallization along the floor even if it was only inclined at a gentle angle.

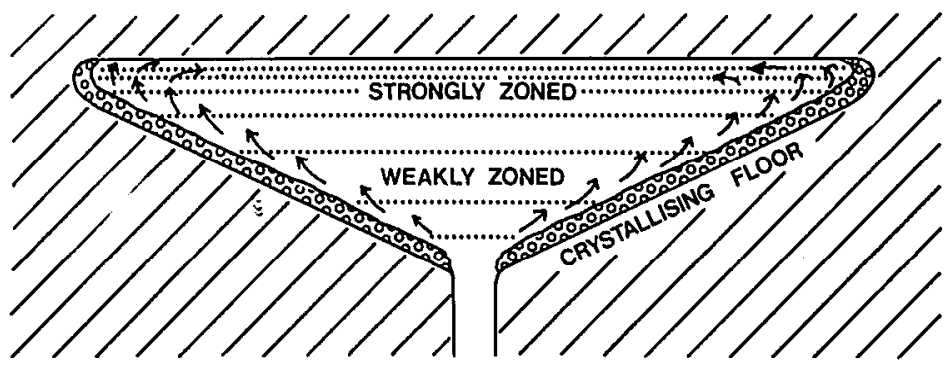

Fig. 9. Schematic diagram of circulation, compositional convection and development of zoning in a magma chamber with a flat roof and inclined floor. 


\section{Acknowledgements}

We are grateful to A.R. McBirney and J.S. Turner, whose reading of an earlier draft of this paper lead to beneficial improvements. H.E.H. and R.S.J.S. are supported by the BP Venture Research Unit and, together with M.A.H., by the Natural Environment Research Council. J.R.W. acknowledges the support of the Carlsberg Foundation and the Danish Natural Science Research Council. Sandra Last typed the drafts.

\section{References}

1 C.F. Chen and J.S. Turner, Crystallization in a double-dirfusive system, J. Geophys. Res. 85, 2573-2593, 1980.

2 A.R. McBirney, Mixing and unmixing of magmas, J. Volcanol. Geotherm. Res. 7, 357-371, 1980.

3 J.S. Turner and L.B. Gustafson, Fluid motions and compositional gradients produced by crystallization or melting at vertical boundaries, J. Volcanol. Geotherm. Res. 11, 93-125, 1981.

4 R.H. Nilson, A.R. McBirney and B.H. Baker, Liquid fractionation, II. Fluid dynamics and quantitative implications for magmatic systems, J. Volcanol. Geotherm. Res. 24, 25-54, 1985

5 H.E. Huppert and M.G. Worster, Dynamic solidification of a binary melt, Nature 314, 703-707, 1985.
6 T.N. Irvine, Experimental modeling of convection in layered intrusions, Carnegie Inst. Washington Yearb. 79, 247-251, 1980.

7 T.N. Irvine, A liquid-density controlled model for chromite formation in the Muskox Intrusion, Carnegie Inst. Washington Yearb. 80, 317-324, 1981.

8 T.N. Irvine, D.W. Keith and S.G. Todd, The J-M platinum-palladium reef of the Stillwater Complex, Montana, II. Origin by double-diffusive convective magma mixing and implications for the Bushveld Complex, Econ. Geol. 78, 1287-1334, 1983.

9 J.R. Wilson and S.B. Larsen, Two dimensional study of a layered intrusion: the Hyllingen Series, Norway, Geol. Mag. 122, 97-124, 1985.

10 J.S. Turner, Buoyancy Effects in Fluids, Cambridge University Press, Cambridge, 1979.

11 W.S. Hildreth, Gradients in silicic magma chambers: implications for lithospheric magmatism, J. Geophys. Res. 86, 10153-10192, 1981.

12 H.E. Huppert and R.S.J. Sparks, Double-diffusive convection due to crystallization in magmas, Annu. Rev. Earth Planet. Sci. 12, 11-37, 1984.

13 I.H. Campbell. A study of macro-rhythmic layering and cumulate processes in the Jimberlana intrusion, Western Australia, I. The upper layered series, J. Petrol. 18, 183-215, 1977.

14 A.H. Wilson, The geology of the Great Dyke, Zimbabwe: the ultramafic rocks, J. Petrol. 23, 240-292, 1982.

15 A.R. McBirney, B.H. Baker and R.H. Nilson, Liquid fractionation, I. Basic principles and experimental simulations, J. Volcanol. Geotherm. Res. 24, 1-24, 1985. 